\title{
Protection of Centella asiatica Extract Through BDNF Expression on Stunting Model Zebrafish Larvae (Danio rerio) by Rotenone Induced
}

\author{
$1^{\text {st }}$ Annisa Ridlayanti \\ Sekolah Tinggi Ilmu Kesehatan \\ 'Aisyiyah Bandung \\ Indonesia \\ annisa_ridlayanti@yahoo.com
}

\author{
$4^{\text {th }}$ Muljohadi Ali \\ Brawijaya University \\ Malang, Indonesia
}

\author{
$2^{\text {nd }}$ Aida Ratna Wijayanti \\ Master of Midwifery study program \\ School of Medicine \\ Brawijaya University \\ Malang, Indonesia
}

\author{
$3^{\text {rd }}$ Husnul Khotimah \\ Brawijaya University \\ Malang, Indonesia
}

Abstract-Objectives: Stunting in WHO Child Growth Standards is based on the length-for-age indexes with less than -2 SD of $z$ score. Rotenone is a pesticide model that acts as an mitochondrial complex I inhibitor and Endocrine Disrupting Chemicals (EDCs). Brain Derived Neurotrophic Factor (BDNF) is one of growth factors mostly found in central nervous system and slightly in peripheral nerves. One of natural herb, Centella asiatica, has antioxidant effects and grows in tropical areas in Indonesia. The aim of this research was to know the effects of Centella asiatica extracts on zebrafish larvae (Danio rerio) by Rotenone induced, through Brain Derived Neurotropic Factor (BDNF) expression. Methods: Zebrafish embryos were divided into five groups including control $(\mathrm{C})$, rotenone group $(\mathrm{R})$, and Centella asiatica group (Ca1;Ca2;Ca3) with concentration of the each $2.5,5$, and $10 \square \mathrm{g} / \mathrm{mL}$. The entire groups had been started since 2 until 72 hpf (half post fertilization) and followed its development up to the age of larvae 9 dpf (days post fertilization). It was followed by measuring the body length at the age of 3, 6 and 9 dpf using Image Raster software. After termination zebrafish larvae, the BDNF expression measurement was measure by using an Immunohistochemistry (IHC) wholemount method with diamino benzidine (DAB). Brown colour density values was quantified by using Image $\mathbf{J}$ software. Results : There was a significant difference in the mean of body length which was shown by Ca2 group $(5 \square \mathrm{g} / \mathrm{ml})$ compared with rotenone group $(p<0,05)$. The BDNF expression increased in all three Centella asiatica groups compared with rotenone group. However, only Centella asiatica group $(5 \square \mathrm{g} / \mathrm{ml})$ showed the most significant effect on the increase of BDNF expression (p $<0.05$ ). Conclusion: Protection of Centella asiatica extract increases the body length and BDNF expression on the stunting model zebrafish larvae induced by rotenone.

Keywords-Centella asiatica, rotenone, zebrafish, stunting, body length, BDNF

\section{INTRODUCTION}

Stunting in WHO Child Growth Standards is based on the length-for-age or height-for-age indexes with the $\mathrm{z}$ score less than -2 SD. The stunting prevalence categories are low $(<20 \%)$, medium $(20-29 \%)$, high $(20-29 \%)$, and very high $(>40 \%)$. The prevalence of stunting in children under five in Indonesia is still relatively high. Based on the complete analysis of national assessment in 2010, approximately $37 \%$ of Indonesian children experienced stunting. The Indonesia basic health research (2013) reported that the national prevalence of stunting increased from $35.6 \%$ (2010) to $37.2 \%$ (2013). The increase of the prevalence showed that one in three children in Indonesia experiences impaired growth due to stunting growth[1]. Factors affecting child development consist of genetic and environmental factors. Environmental factors during prenatal period are maternal nutrition during pregnancy, toxic or chemical substances, radiation, stress, anoxia embrio, immunity, infection, etc[2]. In the Kolsteren chart[1], toxin or chemical substances became a determining factor for the occurrence of stunting. One type of toxin or chemical substances is pesticide[3]. Pesticide, categorized as endocrine disrupting chemicals (EDCs), is a chemical substance which interferes synthesis, secretion, transport, metabolism, binding and elimination of various hormones in the body including thyroid hormone[4]. Rotenone is a natural compound obtained from roots and stems of plants and can be used as an ingredient in a broad spectrum insecticide, piscicide, and pesticides[5]. Rotenone acts as an inhibitor of mitochondrial complex I and a source of Reactive Oxygen Species (ROS)[3]. The effects on the body are reducing the availability of Adenosine Tri Phospate (ATP), oxidative damage, and cell death[6]. 


\section{DESIGN, MATERIALS, AND METHODS}

This research design was true experimental study with post-test-only control group design approach. Animal testing. Zebrafish embryos at age of 2 hpf was obtained from adult zebrafish breeding. The embryos must be transparent, not moldy and white. Death embryos and unfertilized could not be used. Embryos were divided into 5 groups including negative control group (normal), positive control (induced by rotenone $10 \mathrm{ppb} /$ exploration study report), treatment group I (Ca1) (rotenone $10 \mathrm{ppb}+\mathrm{Ca}$ extract $2,5 \mu \mathrm{g} / \mathrm{mL}$ ), treatment group II (Ca2) (rotenone 10 $\mathrm{ppb}+\mathrm{Ca}$ extract $5 \mu \mathrm{g} / \mathrm{mL}$ ), and treatment group III (Ca3) (rotenone $10 \mathrm{ppb}+\mathrm{Ca}$ extract $10 \mu \mathrm{g} / \mathrm{mL}$ ). The exposure was started from 2 until $72 \mathrm{hpf}$ and measured the development of body height up to the age of $9 \mathrm{hpf}$ and then it was terminated. The treatment on the zebrafish embryos had fulfilled the ethical requirements towards animal testing in Health Polytechnic, Ministry of Health Malang. Embryonic medium preparation. Embryonic medium was made from $\mathrm{CaCl}$ 0,08 gr; Kcl 0,06 gr; $\mathrm{NaCl} 2$ gr; $\mathrm{MgSO}_{4} 3,2$ gr which will produce $200 \mathrm{ml}$ of embryonic medium medium $^{[7]}$.Centella asiatica extraction process. Centella asiatica was gained from Materia Medika, Batu, Malang, East Java. The aerial part (not include roots and stolon) was used[8]. Extraction utilised a maceration method with ethanol $96 \%$ as a diluter[8][9]. The results of extraction was crude extract within pasta and diluted with normal saline, stored at $00 \mathrm{C}$. The process of extraction was conducted at pharmacology laboratory, Faculty of medicine, Brawijaya University. Rotenone concentration and Centella asiatica extract. Rotenone (Sigma 8875) concentration used in the study was $10 \mathrm{ppb}$ (based on explorative experiment). Explorative study utilised concentration of 0,$625 ; 1,25 ; 2,5$; $5 ; 10 ; 20 ; 40 ; 80 \mathrm{ppb}$. The results of the first exploration study were congenital abnormalities (concentration 20 $\mathrm{ppb}$ ), low survival rate (concentration $40 \mathrm{ppb}$ ), and death (concentration $80 \mathrm{ppb}$ ) less than $72 \mathrm{hpf}$. The second exploration with various concentrations $(0,625 ; 1,25 ; 2,5$ and $5 \mathrm{ppb}$ ) has not shown a reduction in body length towards stunting growth. Centella asiatica extract 10 $\mathrm{mg} / \mathrm{mL}$ as a stock, using concentration 2,$5 ; 5 ; 10 \mu \mathrm{g} / \mathrm{mL}[8]$. Embryo medium is a mixture of embryonic medium, rotenone, and CA extract which is relevant with the concentration of research groups. The exposure was conducted from 2 to $72 \mathrm{hpf}$. Medium was changed daily. Body length measurement. Body length of Zebrafish larvae were measured at the age of 3, 6 dan $9 \mathrm{dpf}$ using calibrated Image Raster. Larvae were observed with a stereo microscope connected with OptiLab viewer. The body length of larvae or Standard Length (SL) were measured from snout to caudal fin[9]. Zebrafish larvae euthanasia. Zebrafish larvae at the age of $9 \mathrm{dpf}$ were performed euthanasia based on NIH protocol. Wholemount zebrafish larvae were placed into micro tube in iced water minimal 5 minutes and ensured that there was no movement. Then, it was rinsed and fixed with parafolmaldehide (PFA) $4 \%$ at $40 \mathrm{C}$ overnight, followed by exposing $\mathrm{MeOH} 3 \%$ for 5 minutes and $\mathrm{H} 2 \mathrm{O} 23 \%$ for 24 hours to remove the color pigments prior to the procedure Immunohistochemistry (IHC) whole mount. Wholemount Imunohistochemistry (IHC). Larvae at the age of $9 \mathrm{dpf}$ was in methanol, then rinsed with PBSTx $\left(3 \times 5^{\prime}\right)$. Placed larva in the distilated water then washed with PBSTx ( $\left.3 \times 5^{\prime}\right)$. Acetone was given for 20 minutes, stored at $40 \mathrm{C}$ and rewashed with PBS $\left(3 \times 5^{\prime}\right)$. Larvae were given collagenase enzyme $1 \mathrm{mg} / \mathrm{ml}$ and rewashed with PBS $\left(3 \times 5^{\prime}\right)$. Larvae were placed into acetate acid $10 \%(40 \mathrm{C} ; 10$ "), then washed 3 times with PBSTX. NHS $10 \%$ and BSA 3\% (room temperature; 3 hours) were given to the larvae. Primary antibody (1/10) $15 \square$ // NHS 15 $\square$ 1/ PBS $1 \mathrm{ml}$ were needed, then washed 4 times with PBSTX (room temperature; 1 hour). After that, larvae were given secondary antibody around $1 \square 1 /$ NHS $15 \square 1 /$ PBS 1 $\mathrm{ml}$, then washed twice with PBSTX (room temperature; 1 hour). ABC reagent was given including reagent A $20 \square 1 /$ PBS $1 \mathrm{ml}$, then it was followed with reagent B $20 \square$, after that rinsed with PBSTX $\left(3 \times 5^{\prime}\right)$ and stored at room temperature. Larvae were given $\mathrm{DAB}$ colouring for 5 minutes in the room temperature, then washed with PBSTX $\left(3 \times 5^{\prime}\right)$, stored at room temperature. Larvae can be stored in the $87 \%$ gliserol (survive up to 6 months). Wholemount zebrafish larvae at the age of $9 \mathrm{dpf}$ were placed on the slide, then they were observed under inverted microscope connected with digital camera (Panasonic DMC G6 Lumix) to get the pictures. The results of brown colour density were quantified using image $\mathbf{J}$ software within integrated density value. Statistical analysis. The data of body length was analysed using independent $t$ test, Kruskal Wallis test, and Mann Whitney. The difference of BDNF expression among treatment groups used One Way Annova. Significant level in the study was $95 \%$. The analysis utilised SPSS 22.0 software for windows.

\section{RESULTS}

The effects of Centella asiatica extract on the body length There was a difference in the body length of CA group compare to rotenone group with the mean of body length of CA was higher than rotenone group and closed to control. 
TABLE I. THE BODY LENGTH OF ZEBRAFISH LARVAE INDUCED BY ROTENONE AND CA EXTRACT.

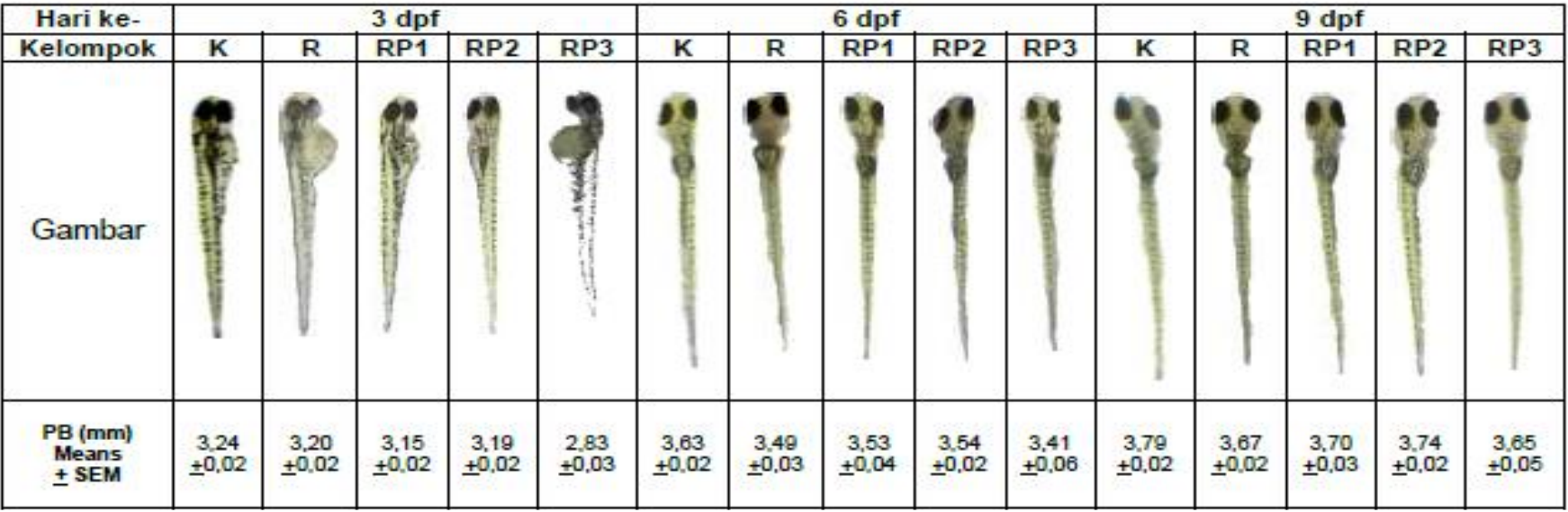

Notes

$\mathrm{K}:$ Control

$\mathrm{R}$ : Rotenone

$\mathrm{RP}_{1} / \mathrm{Ca} 1$ : Rotenone with $\mathrm{Ca} 2,5 \mu \mathrm{g} / \mathrm{ml}$

$\mathrm{RP}_{2} / \mathrm{Ca} 2$ : Rotenone with Ca $5 \mu \mathrm{g} / \mathrm{ml}$

$\mathrm{RP}_{3} / \mathrm{Ca} 3$ : Rotenone with $\mathrm{Ca} 10 \mu \mathrm{g} / \mathrm{ml}$

Based on the graph below, there were growth lines of body length among 5 groups at the age of 3, 6, and $9 \mathrm{dpf}$. Rotenone group had lower in the body length than control

group. On the other hand, the body length of $\mathrm{Ca} 1$ and $\mathrm{Ca} 2$ groups was higher than rotenone group and closed to control group.

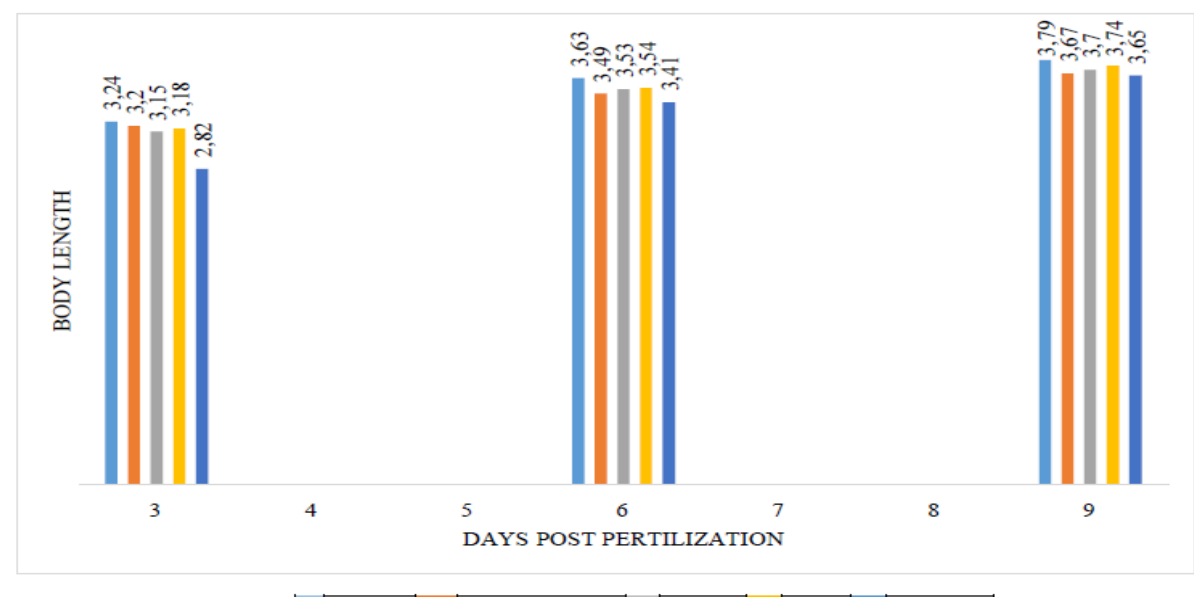

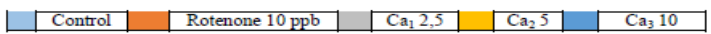

Fig. 1. The graph of the mean of zebrafish larvae body length among control, rotenone, and CA group.

Rotenone group showed lower in the mean of body length than control group. The additional of body length occurred on the $\mathrm{Ca} 1$ and $\mathrm{Ca} 2$ compared with Rotenone group

TABLE II. THE RESULTS OF KRUSKALL WALLIS TEST AND MANN WITHNEY U TEST ON THE BODY LENGTH AMONG GROUPS.

\begin{tabular}{|c|c|c|c|}
\hline \multirow{2}{*}{ Tested groups } & \multicolumn{2}{|c|}{ t test } & \multirow{2}{*}{ Conclusion } \\
\cline { 2 - 3 } & Day 6th & Day 9th & \\
\hline $\begin{array}{l}\text { Rotenone with } \\
\text { Ca1; Ca2; Ca3 }\end{array}$ & 0,233 & 0,191 & \multirow{2}{*}{$(*)$ Significant } \\
$\mathrm{P}<0,05$
\end{tabular}

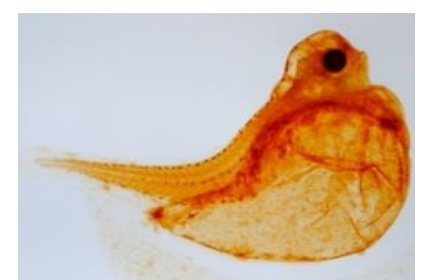

Fig.. 2 Congenital defects on the $\mathrm{Ca} 3$ group 
On the day $6^{\text {th, }}$ there was no difference in the body length between rotenone group and $\mathrm{Ca} 1, \mathrm{Ca} 2$, and $\mathrm{Ca} 3$ groups. In addition, on the day $9^{\text {th }}$, the body length of rotenone group and $\mathrm{Ca} 2$ group showed a significant difference. Therefore, from the results of analysis table. 2 , it can be concluded that $\mathrm{Ca} 2$ group with concentration 5 $\mu \mathrm{g} / \mathrm{ml}$ showed that there was a significant effect on the addition of body length in the rotenone group. Ca3 group $(10 \mu \mathrm{g} / \mathrm{ml})$ has showed the shortest in the mean of body length compared with the other groups since at the age of 3 dpf. Congenital defects were also found in this group.

BDNF Expression
From several analysis below, it can be concluded that there was an increase in the BDNF expression among three groups including Ca1 group (concentration $2,5 \mu \mathrm{g} / \mathrm{ml}$ ), Ca2 group (concentration $5 \mu \mathrm{g} / \mathrm{ml}$ ), and $\mathrm{Ca} 3$ group (concentration $10 \mu \mathrm{g} / \mathrm{ml}$ ) compared with rotenone group, however, only $\mathrm{Ca} 2$ group (concentration $5 \mu \mathrm{g} / \mathrm{ml}$ ) showed the relevance between the addition of body length and BDNF expression. It showed that there was a significant effect of Ca concentration $5 \mu \mathrm{g} / \mathrm{ml}$ on the addition of body length of stunting model zebrafish larvae induced by rotenone. The results of brown colour density measurement on the CA group described in the table III.

TABLE III. THE RESULTS OF BROWN COLOUR DENSITY MEASUREMENT ON THE ZEBRAFISH LARVAE AT THE AGE OF 9 DPF USING IHC-WHOLEMOUNT METHOD

\begin{tabular}{|c|c|c|c|c|c|}
\hline Groups & Integrated density & SD & SEM & $p$-value & Conclusion \\
\hline $\mathrm{K}$ & 288075417 & $3,96 \times 10^{7}$ & $1,77 \times 10^{7}$ & 0,005 & Difference \\
\hline $\mathrm{R}$ & 231511717 & $2,33 \times 10^{7}$ & $1,04 \times 10^{7}$ & 0,005 & No Difference \\
\hline $\mathrm{Ca} 1$ & 262129267 & $1,67 \times 10^{7}$ & $7,48 \times 10^{6}$ & 0,098 & No Difference \\
\hline $\mathrm{Ca} 2$ & 290757179 & $2,79 \times 10^{7}$ & $1,25 \times 10^{7}$ & 0,003 & Diferrenece \\
\hline $\mathrm{Ca} 3$ & 232426827 & $2,56 \times 10^{7}$ & $1,28 \times 10^{7}$ & 0,961 & No Difference \\
\hline
\end{tabular}

Table.III showed that there was a difference in whole groups with $p$-value $<0,05$. It means that integrated density value on the $\mathrm{Ca} 1, \mathrm{Ca} 2$, and $\mathrm{Ca} 3$ was higher than rotenone group, but only $\mathrm{Ca} 2$ group closed to value of control. Integrated density value on the Ca3 group had no difference with rotenone group. This shows that $\mathrm{Ca} 2$ group has the most significant effects on the stunting model zebrafish larvae induced

\section{DISCUSSION}

Protection effects of Centella asiatica extract on the stunting model zebrafish induced by rotenone through BDNF expression The results of the study showed the increase of body length mean on CA group compared with rotenone group and the mean value of body length of zebrafish larvae on CA group closed to control group (table and figure 1). At the age of $3 \mathrm{dpf}$, the body length between rotenone group and CA group is not much different, however, several samples were obtained congenital abnormalities on the $\mathrm{Ca} 3$ group (figure 2). Based on some analysis results above, it can be concluded that $\mathrm{CA}$ increase the body length of zebrafish larvae exposed by rotenone.Centella asiatica is a natural herb that has the effects of antioxidant ${ }^{[10]}$. Some ingredients of antioxidant of CA are polifenol, flavonoid, $\square \square$ caroten, tannin, vitamin $\mathrm{C}[11]$. Moreover, antioxidant capacity in CA is associated with phenolic and flavonoid in CA[12]. Kumar (2009) reported that $\mathrm{CA}$ against colchicine that induce cognitive disorders through oxidative damage[13]. Additionally, Khotimah et al (2015) found that CA extract was used as anti-inflammatory and antioxidant on the dopaminergic neuron from toxic influences of rotenone on zebrafish[6][14].

As described in the previous sections, rotenone increases oxidative stress[15]. Oxidative stress is dangerous because it can activate chemicals such as Reactive Oxygen Species (ROS) which is a free radical. Free radicals have unpaired electrons that are highly reactive and unstable. Free radicals have various chemical structures such as hydroxyl, superoxide, nitrite oxide, and radical peroxil lipid[16]. To reach stability, free radicals damage nearest molecules to gain electrons, this condition is dangerous for the structure and function of the molecule. The reactivity of free radicals can harm all macromolecule cellular including proteins, carbohydrates, lipids, and nucleic acids, including DNA because it can be a precursor genotoxicity. When the presence of free radicals is excess while the antioxidant is low, oxidative stress condition will develop which may lead to chronic diseases and dangerous permanent[17].

The increase of body length on the $\mathrm{Ca} 1$ and $\mathrm{Ca} 2$ groups compared with rotenone group may be caused by the antioxidant function of $\mathrm{Ca}$. If antioxidant in the body increases, the possibility of oxidative stress as the results of rotenone induction would decline and metabolic process in the body would continue[10]. The rotenone induction on zebrafish elevates oxidative stress and cause the harm in mitochondria function[18][19]. The exposure of Centella asiatica declines oxidative stress. Centella asiatica also acts in mitochondria by repairing voltage-dependent anion channel (VDAC) and cleaning free radicals[20]. Tewari et al., (2016) found that Centella asiatica has protection effects on N2a cells by against ischaemia reperfusion (IR) injury and reduce ROS. Moreover, Centella asiatica prevents the increase of intracellular calcium and dan the depletion of mitochondria potential membrane due to oxygen glocose deprivation (OGD)[20]. Centella asiatica also has sitoprotection effects by stabilising human VDAC1 and protect mitochondrial permeability transition pore (mPTP) from oxidative stress[11]. Based on table 2, three groups showed no differences in the mean of body length at the age of 9th compared with rotenone group ( $\mathrm{p}$ value $=$ $0,191)$, on the other hand, on the Ca2 group $(5 \square \mathrm{g} / \mathrm{ml})$ had a significant result with $\mathrm{p}<0,05$ which means that there was a significant difference of body length between $\mathrm{Ca} 2$ group and rotenone group ( $\mathrm{p}$ value $=0,024)$. Therefore, it can be concluded that CA group with concentration 5 $\square \mathrm{g} / \mathrm{ml}$ had a significant effect on the addition of body length on the day of 9 th. In addition, this study found that 
$\mathrm{Ca} 1$ and $\mathrm{Ca} 3$ groups showed the effect of the addition body length was not significant compared with $\mathrm{Ca} 2$ group. Significant effect of Centella asiatica concentration $5 \square \square \mathrm{g} / \mathrm{ml}$ started at the day 9th as Ca had low bioavaibility. Another finding in this study was the availability of congenital abnormalities of the sample in figure 2. This sample was in Ca3 $(10 \square \mathrm{g} / \mathrm{ml})$ group. In addition, the mean of body length was less than normal average $(2,83 \mathrm{~mm})$ on the day 9 th due to toxicity effect of CA or unknown genetic factor. This study did not measure specific causes of mutated gene. In other research there was no toxicity on experimental animals exposed by Centella asiatica such as death and no clinical symptoms of poisoning at dose levels up to $2000 \mathrm{mg} / \mathrm{kgBW}$ [7]. Another study reported that there was no poisoning effect on mice with dose 3-7 g/ $\mathrm{kgBW}$. Ca plants juiced which was consumed by experimental animals around $2 \mathrm{ml}$ had no toxic effects[21]. The side effects of this plant were gastrointestinal disorders and nausea, redness on the use of topical, jaundice with the elevation of liver enzyme with unknown dose consumed for 20-60 days[11].

This study found that there was an increase in BDNF expression on stunting model zebrafish larvae induced by rotenone. BDNF expression in the all $\mathrm{Ca}$ groups groups increased compared with rotenone (table 3 ). However, the most significant shown in the $\mathrm{Ca} 2$ group with concentration $5 \square \mathrm{g} / \mathrm{ml}$. The data proved that Centella asiatica is rich of antioxidant that reduce oxidative stress due to rotenone induction so transcription process and translation of mRNA BDNF continued and BDNF expression could increase[22]. BDNF regulates TGF $\square \square$ and BMP-2 contributes in the bone development, so the bones grow normally ${ }^{[23][24][25]}$. The increase of BDNF expression was relevant with data of body length mean that increased on the day $6^{\text {th }}$ and $9^{\text {th }}$ compared with rotenone group. Nevertheless, based on One Way Annova test, the significant effect of $\mathrm{Ca}$ on the BDNF expression was shown in the $\mathrm{Ca} 2$ group on the day $9^{\text {th }}$. Another finding, $\mathrm{Ca} 3$ group $(10 \mu \mathrm{g} / \mathrm{ml})$ had anomaly abnormalities, hence, an increase of BDNF expression was not significant compared with rotenone group.

Therefore, it can be concluded that Brain Derived Neurotropic Factor (BDNF) contributes in patomechanism the occurrence of stunting model zebrafish larvae induced by rotenone with the decline of BDNF expression induced by rotenone. Moreover, there are protective effect of Centella asiatica extract with elevates BDNF expression on stunting model zebrafish larvae induced by rotenone.

\section{CONCLUSION}

Centella asiatica extract $[5 \mu \mathrm{g} / \mathrm{mL}]$ has a protection in the elevation of body length zebrafish larvae (Danio rerio) at the age of $9 \mathrm{dpf}$ through BDNF expression.

\section{ACKNOWLEDGMENT}

We thank to Mr. Wibi Riawan (Department Biochemistry, School Of Medicine Brawijaya University) for helping in immunohistochemistry (IHC) wholemount proccess. Aisyiyah Bandung Health Science College that has supported the fund for this research.

\section{REFERENCES}

[1] P. Kolsteren, "The determinant of stunting: can we regard the linear growth perfomance as a continuum of fetal development?. Asia pasific J Clin Nutr." hal. 59-69.

[2] "Mechanism of Toxicity in Rotenone Models of Parkinson 's," Disease, vol. 23, no. 34, hal. 10756-10764.

[3] "Rotenone Detection in Surface and Ground Waters Rotenone Detection," in Surface and Ground Waters, vol. 3, hal. 1-3.

[4] P. Pruunsild, A. Kazantseval, T. Aid, K. Palm, dan T. Timmusk, "Dissecting the human BDNF locus: Bidirectional transcription, complex splicing, and multiple promoters," Genomics, vol. 90, no. 3, hal. 397-406, 2007.

[5] P. Perrone, M. Laboratories, dan H. Division, "Rotenone Detection in Surface and Ground Waters Rotenone Detection in Surface and Ground Waters," no. 3, hal. 1-3, 2011.

[6] H. Khotimah, S. B. Sumitro, M. Ali, dan M. A. Widodo, "Standardized Centella Asiatica Increased Brain- Derived Neurotrophic Factor and Decreased Apoptosis of Dopaminergic Neuron in Rotenone- Induced Zebrafish," vol. 2, no. 1, hal. 2227, 2015.

[7] F. Pittella, R. C. Dutra, D. D. Junior, M. T. P. Lopes, dan R. Nádia, "Antioxidant and Cytotoxic Activities of Centella asiatica ( L )," hal. 3713-3721, 2009.

[8] "Introduction to "steroid hormone actions in the CNS: The role of brain-derived neurotrophic factor (BDNF).," Neuroscience, vol. 239 , hal. $1-2$.

[9] Kohen dan A. Nyska, "Oxidation of Biological Systems : Oxidative Stress Phenomena, Antioxidants , Redox Reactions , and Methods for Their Quanti cation," vol. 30, no. 6. hal. 620650 .

[10] S. Tiwari, S. Gehlot, dan I. S. Gambhir, "Centella Asiatica: A Concise Drug Review With Probable Clinical Uses Centella Asiatica : A Concise Drug Review With," vol. 7, no. 1, hal. 3844, 2011.

[11] M. Rahman, S. Hossain, A. Rahaman, N. Fatima, T. Nahar, dan B. Uddin, "Antioxidant Activity of Centella asiatica ( Linn .) Urban : Impact of Extraction Solvent Polarity," vol. 1, no. 6, hal. 27-32.

[12] P. Hashim, H. Sidek, M. H. M. Helan, A. Sabery, U. D. Palanisamy, dan M. Ilham, "Triterpene composition and bioactivities of centella asiatica," Molecules, vol. 16, no. 2, hal. 1310-1322, 2011.

[13] A. Kumar, A. Prakash, dan S. Dogra, "Centella asiatica Attenuates D-Galactose-Induced Cognitive Impairment, Oxidative and Mitochondrial Dysfunction in Mice.," Int. J. Alzheimers. Dis., vol. 2011, hal. 347569, 2011.

[14] H. Khotimah, M. Ali, S. B. Sumitro, dan M. A. Widodo, "Decreasing $\alpha$-synuclein aggregation by methanolic extract of Centella asiatica in zebrafish Parkinson's model," Asian Pac. J. Trop. Biomed., vol. 5, no. 11, hal. 948-954, 2015.

[15] A. F. Hern??ndez, T. Parr??n, A. M. Tsatsakis, M. Requena, R. Alarc??n, dan O. L??pez-Guarnido, "Toxic effects of pesticide mixtures at a molecular level: Their relevance to human health," Toxicology, vol. 307, hal. 136-145, 2013.

[16] M. Abdollahi, A. Ranjbar, S. Shadnia, S. Nikfar, dan A. Rezaie, "Pesticides and oxidative stress: a review.," Med. Sci. Monit., vol. 10, no. 6, hal. RA141-A147, 2004.

[17] M. P. B. 55] Verderio Caludia Fabio Boanco, Cross Talk Between Vestibular Neurons And Schwann Cells Mediates BDNF Release And Neuronal Regeneration. Brain Cell Biology, vol. 35, no. 2. Springer International Publishing.

[18] M. Garmier et al., "Complex I dysfunction redirects cellular and mitochondrial metabolism in Arabidopsis.," Plant Physiol., vol. 148, no. 3, hal. 1324-1341, 2008.

[19] D. Hinson, "Rotenone characterization and toxicity in aquatic systems. Principles of environmental toxicology," 2000. "Cytoprotective effect of Centella asiatica is mediated through the modulation of mitochondrial voltage-dependent anion channel," J. Funct. Foods, vol. 21, hal. 301-311.

[21] G. S??nchez-Duffhues, C. Hiepen, P. Knaus, dan P. ten Dijke, "Bone morphogenetic protein signaling in bone homeostasis," Bone, vol. 80, hal. 43-59, 2015.

[22] S. M. Rothman, K. J. Griffioen, R. Wan, dan M. P. Mattson, "Brain-derived neurotrophic factor as a regulator of systemic and brain energy metabolism and cardiovascular health," Ann. 
N. Y. Acad. Sci., vol. 1264, no. 1, hal. 49-63, 2012.

[23] a K. McAllister, "Cellular and molecular mechanisms of dendrite growth.," Cereb. Cortex, vol. 10, no. 10, hal. 963-973, 2000 .

[24] C. C. Thompson dan G. B. Potter, "Thyroid hormone action in neural development.," Cereb. Cortex, vol. 10, hal. 939-945,
2000.

[25] M. P. Mattson, S. L. Chan, dan W. Duan, "Modification of brain aging and neurodegenerative disorders by genes, diet, and behavior.," Physiol. Rev., vol. 82, no. 3, hal. 637-672, 2002. 